\title{
LOGUERCIO, V. S. Doping e as muitas faces da injustiça: o processo inquisitorial iníquo e violento do sistema de controle vigente. Porto Alegre: AGE Editora, 2008.
}

\author{
Cristiano Israel Caetano \\ Universidade Federal do Paraná, Curitiba, Paraná, Brasil. \\ Fernando Renato Cavichiolli \\ Universidade Federal do Paraná, Curitiba, Paraná, Brasil.
}

Trata-se de obra do Dr. Sabino Vieira Loguercio. A apresentação do livro é feita por Juca Kfouri, o qual afasta a falsa percepção de "heresia" aparentemente exposta pelo título. Dr. Sabino, colorado inveterado, médico, membro fundador da Sociedade Brasileira de Endoscopia Digestiva, é reconhecido como autoridade no ramo da gastroenterologia, além de possuir talento musical e literário.

No primeiro capítulo, "O Doping e o Processo Inquisitorial de Controle Punitivo", a partir das memórias da infância (década de 40), o autor relata as sensações de ouvir futebol no rádio, a percepção de honestidade dos comentaristas e jogadores, as limitações e emoções de uma transmissão radiofônica. Um retrato de sua família junta a intimidade com o futebol também é desenvolvido. O respeito pelo falecido pai de origem italiana, a exaltação de ânimos, o cuidado peculiar com a videira, os beijos molhados da avó e o "castigo do cacho" são descritos, características típicas de uma família ítalo-tupiniquim. Na sequência, o escritor relata a surpresa na final da copa de 54 e as primeiras suspeições de doping, incitando o leitor a compreender melhor as distinções entre doença e o delito, além de fatores biológicos em torno do fígado.

No segundo capítulo, "O Doping e o Alvorecer da Consciência", o autor aborda as descobertas com o livro Hígado y Drogas, de Victor Pereze, e o despertar da correlação com os exames antidoping diante da capacidade do órgão em metabolizar. Na sequência, detalha as reações químicas e a impossibilidade de estabelecer um veredito médico com apenas um exame laboratorial. Cita casos emblemáticos como, por exemplo, de Júnior Baiano (2001), Anderson (1997) e os equívocos praticados. Percorre densa descrição biológica com atenção para os efeitos inesperados do fígado quando decorre indução enzimática sobre os hepatócitos, na denominada interação de drogas, exemplificando a ingestão concomitante de anfetamina com bicarbonato de sódio, a qual não é detectada em um exame de urina, dependendo de investigação nas fezes.

No terceiro capítulo, “A Interação de Drogas", Dr. Sabimo realiza uma descrição de falsos positivos (transporte de drogas pela albumina, atuação da fenilefrina, uso de androgênios) e de informações clínicas mescladas a passagens de sua vida (registradas em um artigo no Correio do Povo publicado na década de 80, carta a Juca Kfouri em 1986, resposta a Luís Fernando Veríssimo e o depoimento do escritor no Tribunal de Justiça Desportiva em 1991), com o auge no famoso embate entre ele (Dr. Sabino) e o jornalista Sant'Ana devido à recusa dos jogadores do Internacional em se submeter ao exame de urina após a final do Gaúcho de 1991 contra o Grêmio. 
No quarto capítulo, "Os Princípios Consolidados", desenvolve o sigilo decorrente do dualismo médico-paciente, e o propósito do profissional que jamais é de punir. Para ele, o ser humano está acima de qualquer esporte ou evento e mesmo nos casos de ingestão consciente de drogas deve ser qualificado como doente e não marginal. Prosseguindo, Dr. Sabino diferencia o sistema que denominou de inquisitivo (modelo atual) e o formato ideal denominado perquisitivo (diagnóstico mais seguro); o autor decreta (2008, p. 75): "o teste toxicológico urinário, com finalidade punitiva, é insuficiente, ineficaz, perigoso e antiético." Conclui ingressando na dimensão legal (doutrina, jurisprudência, código de ética).

No quinto capítulo, "A Questão Maior dos Direitos Humanos", o autor destaca os Direitos Humanos como norma jurídica de maior grandeza. Sistematiza o doping em uma figura geométrica (hexágono), circundando pelas dimensões ética, científica (campo da prevenção), desportiva e midiática (campo da repercussão), administrativa (decisão parcial) e jurídica (julgamento derradeiro). Relata o reconhecimento do Comitê Olímpico Internacional de que não há mais razão para considerar a cocaína como doping e estabelece a incoerência em manter drogas de consumo pessoal (não interferem no rendimento esportivo) na lista de exclusão e pior, afastando atletas de seu ambiente de trabalho. Registra falhas metodológicas envolvendo pesquisas de fármacos, citando publicação do Instituto Americano de Medicina do Esporte, descartando a possibilidade de melhor desempenho atlético em decorrência da ingestão de esteróides anabólicos por homens sexualmente maduros, não obstante seus vários efeitos perversos. Reporta o caso Ben Johnson (1998), da atleta Sandra Torres e da condenação da Federação Internacional de Atletismo, que em 1992 indenizou o atleta Harry Butch Reynolds em 27,3 milhões de dólares, como equívocos a serem evitados. Encerra com a atuação da imprensa no caso Zetti/Rimba (falso doping em 1993 após derrota da seleção brasileira na Bolívia por 2x0) apresentando os estudos do Dr. Otávio Brasil.

No capítulo seis, "A Prova Cabal: O Caso Anderson", Dr. Sabino expõe o caso Anderson (jogador do Internacional), acusado de usar morfina e afastado preventivamente dos campos. $\mathrm{O}$ acinte das divulgações jornalísticas, posteriormente desmistificadas por testes realizados por repórteres, assenta de maneira categórica as preocupações do autor. Nessa passagem, ele descreve sua defesa em relação a Maradona, com amparo no estudo de B.B. Hoffmann quanto à pseudoefedrina (descongestionante nasal) e o conceito de doping esportivo (consumo de fármaco para melhorar o rendimento). Para ele, se um atleta está com dificuldade de respirar e utiliza um descongestionante o propósito dele não é assumir uma vantagem em relação aos demais e sim colocar-se em situação de normalidade. Finaliza com o caso Rafael Scheidt (Grêmio - primeiro caso de doping por DHEA ${ }^{1}$ no mundo), descrevendo o DHEA como hormônio mãe, produzido por intermédio do colesterol e presente em alimentos do cotidiano.

No sétimo capítulo, "O Enterro Ostentatório do Direito de Defesa", aborda as punições prematuras no esporte por meio dos casos de Maurren Higa Magi (atleta acusada de doping por testosterona), Javier Sotomayor (metabólito de cocaína na urina), Laura Azevedo e Rebeca Gusmão. Relata o caso da famosa saltadora e medalhista olímpica, incriminada falsamente de passar repetidas vezes uma pomada cicatrizante (Clestebol). Contrapõe a suposta infração com base no livro Biotransformação das Drogas e no teste feito por uma repórter, registrando os abalos psicológicos sofridos pela atleta. No caso do cubano, relembra que mais de 250 plantas (família das eritrociláceas), se ingeridas, podem originar a benzoilecgonina, indicando metabólitos na urina. Destaca que os efeitos desta substância são idênticos à noz de cola, encontrada na fórmula de refrigerantes. Para ele, Vargas e Delgado (halterofilistas de Cuba) podem ter sido vítimas de falsa acusação de doping por Nandrolona. A terceira ocorrência foi da nadadora Laura Azevedo (Troféu Brasil, 2003); o antidoping

\footnotetext{
${ }^{1}$ Nome científico: dehidroepiandrosterona.
} 
acusou presença de três esteroides, os quais não foram confirmados em exames posteriores. Posteriormente, ele descreve a acusação de doping por testosterona contra Rebeca Gusmão; a suspeita de contaminação da amostra de urina e a declaração da Dra. Renata Castro (médica Diretora da CBDA), apontando irregularidades nos fatos envolvendo a nadadora, como o fato de em três amostras (colhidas em menos de 24 horas) uma resultar negativa, a segunda inconclusiva e a terceira positiva, com duas delas contaminadas por bactérias. Encerra com o episódio Romário em 2007, punido pela ingestão de Finasterida utilizada no tratamento de queda de cabelo (impede a transformação de testosterona em diidrotestosterona).

Na última etapa, o escritor detalha sua participação em discussões envolvendo o doping, transcrevendo o caso Dione D’Agostini Chillemie, a detecção de Furosemida, descrevendo uma série de equívocos na cadeia de custódia e coleta, a exemplo de um caso em que todos os frascos possuíam numeração 123456. Elucida que a Furosemida (ação diurética) em si não é um estimulante, porém, pode servir para disfarçar a presença de substâncias proibidas. Relata a absolvição da maratonista Sandra Torres, a qual ingeriu noretindrona (permitida), porém que no seu organismo se transformou em 19-norandrosterona (proibida) e da ciclista colombiana Luísa Calle, que consumiu medicamento para cefaléia (autorizado), todavia o seu metabolismo modificou para heptaminol (estimulante vedado).

Por fim, o Dr. Sabino reafirma a necessidade de coibir práticas dopantes que melhorem o rendimento pessoal, entretanto, com antidoping preventivo assegurado na ética médica. Para o Dr. Sabino, o atual protocolo transgride os preceitos clínicos de integridade da pessoa humana, além das dimensões morais e jurídicas. Cita a fragilidade do sistema, a exemplo do THG (tetra-hidrogestrinona) anabólico desenvolvido para não ser identificado no teste de urina, bem como referencia os estudos da Universidade de Hopkins, direcionados à prevenção no abuso de drogas. Por derradeiro, propõe algumas recomendações para garantia da ética médica envolvendo o doping, exemplificando: o médico não deve divulgar exames clínicos, exceto se o atleta autorizar expressamente a publicação ou reservadamente no âmbito de uma ação judicial.

Em resumo, o Dr. Sabino problematiza o atual sistema punitivo dito arbitrário, propondo um modelo preventivo antidrogas, acompanhado por equipes médicas com especialização e conhecimento na área, além de manutenção do sigilo por questões de ética da medicina. Fundamenta no argumento de que o corpo é individualizado, a ponto de responder diferentemente a estímulos igualmente diversos, ancorado em sólida dedução a partir dos efeitos químicos e biológicos que o fígado provoca nos indivíduos, sendo todo o texto científico acompanhado por casos reais, considerando injustificável o reducionismo falho de um exame antidoping limitado a uma solitária amostra urinária.

A leitura da obra traz a reflexão se o exame de urina, como único elemento de prova para penalização de atletas, é absolutamente seguro diante do efeito profissional e psicológico devastador que uma sanção errônea pode gerar, associado aos reverberados aspectos éticos que envolvem a classe médica e jornalística na divulgação indiscriminada de exames privados. As questões problematizadas são frequentes na atualidade e abrem portas para que novos e diversificados estudos sobre a questão moral do doping na esfera esportiva sejam potencializados, principalmente através de estudos propositivos no campo da Educação Física e do Direito que contemplem exames clínicos mais específicos, ao tempo em que garantam o contraditório e a ampla defesa aos atletas antes da aplicação de uma punição.

\section{Referências}

LOGUERCIO, V. S. Doping e as muitas faces da injustiça: o processo inquisitorial iníquo e violento do sistema de controle vigente. Porto Alegre: AGE Editora, 2008. 
Recebido em: 29/11/2018

Revisado em: 01/02/2019

Aprovado em: 06/03/2019

Endereço para correspondência:

cristianopmpr@gmail.com

Cristiano Israel Caetano

Universidade Federal do Paraná, Setor de Ciências Biológicas,

Departamento de Educação Física.

Rua Coração de Maria, 92

Jardim Botânico

80270-315 - Curitiba, PR - Brasil. 